\title{
Focusing on Corporate IT Capability and Alliance Performance: An Empirical Analysis Based on Corporate Alliances in China
}

\author{
Xing Hua ${ }^{1}$, Qi Yue ${ }^{2, *}$ \\ ${ }^{1}$ Department of Finance and Economics, Guangdong Youth Vocational College, Guangzhou, China \\ ${ }^{2}$ School of Economics and Management, South China Normal University, Guangzhou, China
}

Email address:

13356981@qq.com (Qi Yue)

${ }^{*}$ Corresponding author

\section{To cite this article:}

Xing Hua, Qi Yue. Focusing on Corporate IT Capability and Alliance Performance: An Empirical Analysis Based on Corporate Alliances in China. International Journal of Business and Economics Research. Vol. 6, No. 4, 2017, pp. 53-57. doi: 10.11648/j.ijber.20170604.12

Received: May 15, 2017; Accepted: June 14, 2017; Published: July 18, 2017

\begin{abstract}
This paper studied the relationship between corporate information technology (IT) capability and alliance performance based on a sample of Chinese corporate alliances. With regression analysis, this paper found IT capability has significantly positive effect on alliance performance and knowledge acquisition plays a role as a mediator, while regional industrial factor plays a role as a moderator. That means the positive effect of IT capability on alliance performance is stronger in cross-region alliances than same-region alliances and is stronger in high-dynamic industry than low-dynamic industry. The foundings can provide some valuable suggestions for executives and related policy-makers, especially in emerging markets.
\end{abstract}

Keywords: Regression Analysis, IT Capability, Alliance Performance, Knowledge Acquisition

\section{Introduction}

With the dynamic environment and competition intensifies day by day, individual enterprises can hardly rely on its own strength to achieve sustained and stable development. So the strategic alliance has become one of the most important enterprise growth modes. Just as the experts like Poppo, Zhou and Li (2016) argued that strategic alliance is thought to reduce the transaction cost, to increase the economy of scale and scope economy, to enhance the ability of the enterprise to deal with operating risk [1]. Especially in the process of globalization, strategic alliance is regarded as the first choice of entering a foreign market. In reality, the strategic alliance of this form of organization already favored many managers. Research on strategic alliance field indicates that some enterprises alliance was more successful than other company. Factors influencing the scholars have done a lot of research on alliance performance. Dyer, Singh and Kale (2008) and other scholars pointed out one of the key factors which affect enterprise alliance performance is the enterprise information and the ability to use information in the alliance process, including a variety of explicit knowledge and tacit knowledge which rely on the enterprise's information technology ability to support [2]. Although the strategic alliance may exist as independent legal person and other organization form of joint venture company, the essence is still is a cooperation between enterprises which means reallocation of resources and utilization, especially the access and delivery of various information sharing, Therefore, enterprise information technology ability plays a key role in theory.

However, scholars had different conclusions and views on the relationship between the information technology capability and firm performance, Weill (1992) found that high technology enterprises in the industry of high investment in IT often means high profit [3]. Bharadwaj (2000) believe that the information technology ability is stronger, the higher profit margins and the cost is low [4]. Santhanam and Hartono (2003) also verified the positive relationship between information technology capability and firm performance [5]. Jean (2010) empirical research has confirmed the manufacturers IT resources contribute to its more effectively for its customer service and obtain more revenue [6]. However, Ravichandran (2009) also believes 
there is only a weak association between corporate performance in information technology and enterprise performance [7].

Liang (2010) indicated the presence of uncertainty relation between IT resources and enterprise performance, but the intermediary effect of enterprise IT capability between IT resources and enterprise performance has a stronger explanation [8]. From the existing literature can be seen, although there has been a certain number of works studied for the enterprise information technology capabilities, the research results have not yet obtained the consistent conclusion which mostly pointed to a direct relationship between information technology capability and enterprise performance of enterprises and less research on information technology capability in strategic alliance of enterprises. Therefore, in order to reveal the ability of IT alliance in Chinese context is helpful to achieve their alliance target, this paper attempts to study the ability of IT enterprise of China enterprise alliance during the transition period. For the ongoing alliance or possible future alliance of Chinese Enterprises, Whether you need to pay attention to and increase the IT investment so as to strive to improve their ability of information technology is a practical problem. In case of that, this study has a certain practical value.

\section{Theory and Hypothesis Development}

\subsection{Mediating Effect of Knowledge Acquisition on the Relationship Between IT Capability and Alliance Performance}

Schilke and Cook (2015) believes that alliance performance will be affected by many internal and external factors [9]. Whether the enterprise can acquire enough valuable knowledge in the process of alliance cooperation is one of the key variables. Meier (2011) also emphasize that knowledge is the best resource to maintain the sustainable competitive advantage of an enterprise [10]. In order to obtain valuable knowledge, enterprises must implement knowledge acquisition in the internal and external environment, and the formation of strategic alliances is an important way to obtain external knowledge. However, Becerra, Lunnan and Huemer (2008) argued that, in the alliances, not all can acquire useful knowledge from coalition partners [11]. Weber and Weber (2007) pointed out that there are many factors that influence the process of knowledge acquisition from enterprise alliance in the enterprise, IT ability is important the factors influencing knowledge acquisition level [12]. Good IT capability means that enterprises can efficiently identify, encode and store the acquired information, and facilitate the understanding and use of information by employees, which is conducive to the formation and transmission of knowledge. Lyles and Salk (2007) put forward that IT capability can strengthen the connection and communication between employees, and thus promote the flow and diffusion of knowledge, and then form a knowledge base in the enterprise [13]. In the strategic alliance, the enterprise has good IT ability between alliance partners to provide a platform of information and knowledge transfer and sharing and complementary knowledge to acquire effective information and its coalition partners on this platform. For example, in vertical alliances, IT capabilities can facilitate information on the operations and requirements of upstream and downstream alliance partners, thereby enhancing the efficiency of alliance operations. Based on this, this study proposes the following hypotheses:

Hypothesis 1: knowledge acquisition has mediating effect between firm IT capability and alliance performance.

\subsection{The Enterprise IT Capability and Alliance Performance: Moderating Effect of Regional Factor}

In China, due to the existence of a certain degree of market segmentation of reality, the regional factors become one of the important factors affecting corporate behavior and performance. Cross-regional business and cooperation in Chinese enterprises in China, the relationship between the proper coordination with foreign partners or the field of alliance and the efficient use of the relevant information, is the key point to influence business performance and difficult, has also been a considerable attention of academia and business circles. Bouncecken, Clau and Fredrich (2016) argued that the main purpose of the enterprise cross-regional alliance is to improve the overall economic efficiency of enterprises and expand the business scope [14]. In this case, the local affiliates must respond quickly to local needs, improve the efficiency of integration of the parent company and constantly seek new market opportunities and profit growth point. Only in this case, enterprise can achieve the overall business goals. When the parent companies and joint venture companies in different areas, its positive effects of information technology capability on alliance capability is stronger than in the same region. The opportunism behavior of cross-regional cooperation coalition partner may stronger. And the parent company needs stronger control ability. So the stronger the information technology ability is, the more information and resources for the acquisition and control ability will be, which then thus more conducive to the enhancement of alliance. Based on this, this study proposes the following hypothesis:

Hypothesis 2: regional factors on the relationship between IT capability and alliance performance play a role in the regulation of.

\subsection{The Enterprise IT Capability and Alliance Performance: Moderating Effect of Industrial Factor}

Industry dynamics is considered to be an important external environmental factor that influences firm behavior and firm performance. Krishnan, Geyskens and Steenkamp (2016) pointed out that dynamic industry refers to the degree of unpredictability of the environment of enterprises in the industry changes, and the empirical test of the dynamic environment has a moderating effect on corporate behavior and corporate performance [15]. When the industry in the 
higher level of uncertainty in the industry, consumer preferences, enterprise competition strategy and the product renewal speed will be faster, leading to changes in the enterprise faced in information and information processing will be increased accordingly, the need for the enterprise information technology capacity of higher level. For example, in the high dynamic of computer hardware or software industry, the updating speed of product change rapidly, and the number of competitors is also changing, changes in customer demand is gradually increased, at the same time, get all kinds of information for the enterprise's competitive ability has important even decisive importance. In the strategic alliance, the IT capability of the enterprise is the guarantee for the enterprise to obtain the information and knowledge of the above products, competition and market from the cooperation of the alliance, and is also the key to the firm's competitive advantage. Relatively speaking, the stronger the environment dynamics, the more positive the IT capability is to the alliance capability. Based on this, this study proposes the following hypotheses:

Hypothesis 3: industry dynamic relation of enterprise IT capability and alliance performance has a regulatory role, namely: compared with the industry dynamic low, positive role of enterprise industry dynamic in the high IT capability on alliance performance will be stronger.

\section{Research Design}

\subsection{Sample}

In this study, obtaining first-hand data for empirical analysis through the questionnaire, respondents in China currently own or have experience in alliance. Respondents were executives or directly involved in the alliance of enterprises responsible person. Through interviews, e-mail, the paper mail, telephone and other means, a total of 400 questionnaires were issued, 139 valid questionnaires were obtained.

\subsection{Variables}

Alliance performance (AP): according to Kale and Singh (2007) [16], whether achieve alliance targets to measure or not is used to measure the variable, including market three aspects, customer satisfaction, profit rate.

IT Ability (IT): according to Bharadwaj (2000) and Santhanam and Hartono (2003) [4, 5], the measurement of IT capabilities including IT foundation (IT_F), IT human resource (IT_H) and IT structural support (IT_S).

Knowledge Acquisition (KA): according to Kale and Singh (2007) [16], according to the industry knowledge, technical knowledge, management knowledge and the union related knowledge, it is measured the degree of knowledge which respondents have obtain during the alliance cooperation time.

Region (REG): regional factors is set to $0-1$ virtual variable, which is judged by whether the respondent's cooperative enterprises and alliance is in the same administrative district. This research takes cities as the basic administrative units in the region.

Industry (IND): 0-1 dummy variables, judged by the surveyed enterprises that the main business of the industry is in, 1 in manufacturing, service industry is 0 .

\section{Results and Analysis}

\subsection{Analysis of Mediating Effect}

Construct the structural equation model of IT capability, knowledge acquisition and alliance performance. The analysis result is shown in Figure 1. From the results it can be seen that the coefficient between IT capability and alliance performance is $0.511(\mathrm{P}<0.001)$; the coefficient between IT capability and knowledge acquisition was $0.872(\mathrm{P}<0.001)$; the coefficient between knowledge acquisition and alliance performance was $0.464(\mathrm{P}<0.001)$. According to Wen (2004) proposed the intermediary effect test program: IT ability was the coefficient relation of knowledge acquisition, knowledge acquisition and the coefficient on alliance performance significantly, so it can be judged that the knowledge acquisition has a mediating effect on the relationship between IT capabilities and alliance performance; at the same time in Figure 1, the relationship between coefficient of IT capability on alliance performance was significant. Therefore, knowledge acquisition has partly mediating effect, rather than completely mediating effect. Based on this, hypothesis 1 is supported.

Table 1. Analysis results based on samples classified by region and industry.

\begin{tabular}{|c|c|c|c|c|c|}
\hline \multirow{2}{*}{\multicolumn{2}{|c|}{ Variable relations }} & \multicolumn{2}{|l|}{ Region } & \multicolumn{2}{|l|}{ Industry } \\
\hline & & Cross region $(n=36)$ & Same region $(n=65)$ & High dynamic $(n=66)$ & Low dynamic $(n=73)$ \\
\hline IT ability & ance performance & $0.735^{* * *}$ & $0.882 * * *$ & $1.103 * * *$ & $0.763 * * *$ \\
\hline \multirow{6}{*}{ indicators } & $\chi^{2}$ & 62.698 & 80.232 & 58.654 & 83.921 \\
\hline & $\chi^{2} / \mathrm{df}$ & 1.844 & 2.36 & 1.725 & 2.468 \\
\hline & RMR & 0.073 & 0.079 & 0.067 & 0.077 \\
\hline & GFI & 0.751 & 0.818 & 0.815 & 0.827 \\
\hline & TLI & 0.829 & 0.875 & 0.921 & 0.897 \\
\hline & CFI & 0.870 & 0.906 & 0.941 & 0.922 \\
\hline
\end{tabular}




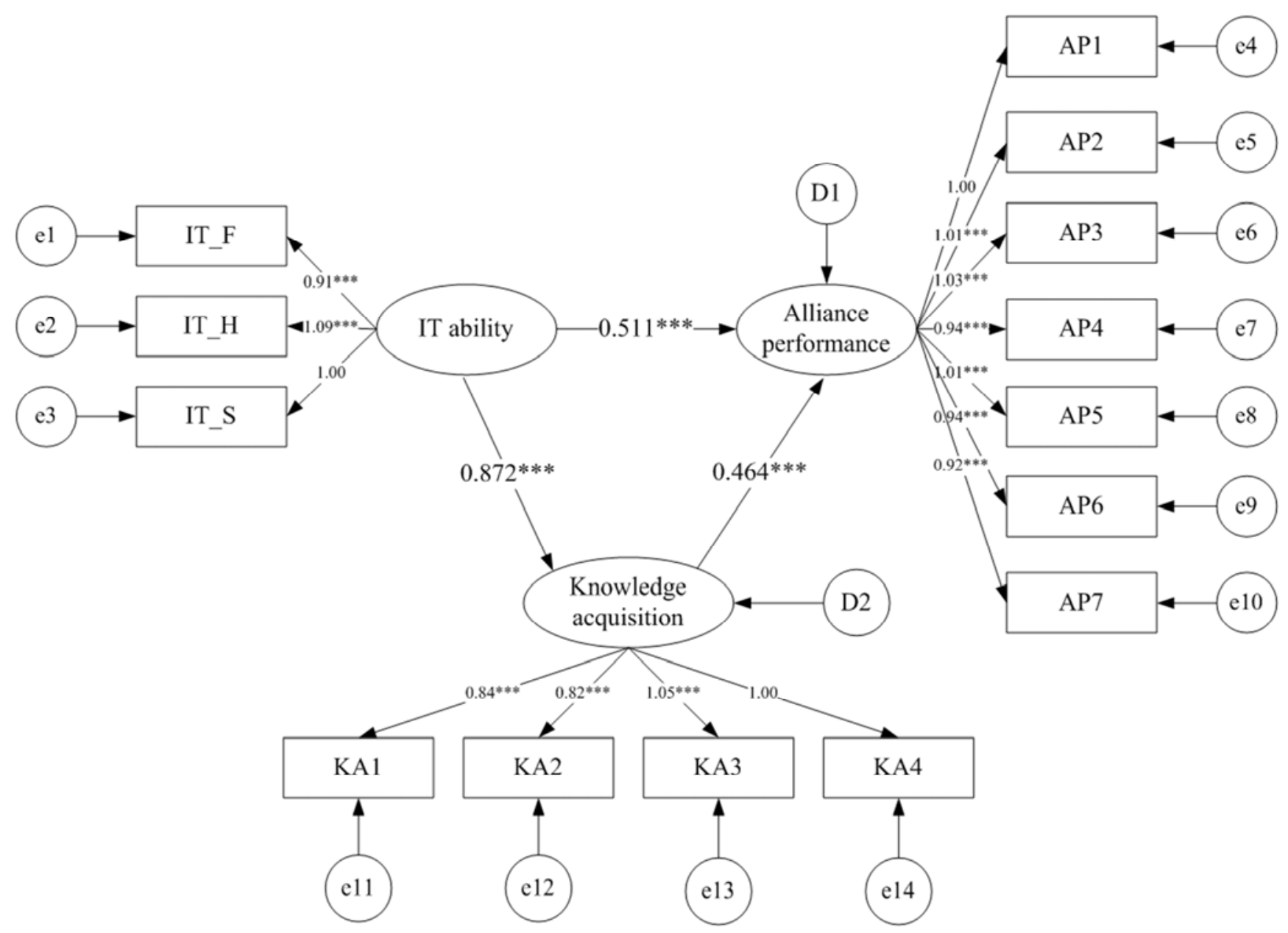

Figure 1. Analysis results of IT ability and alliance performance.

\subsection{Analysis of Moderating Effect}

In order to test the moderating effects of regional characteristics and industry characteristics on IT capability and alliance performance, this study classifies samples based on cross regional and industry dynamics. The alliance of the enterprises in the same city as cross regional alliance, a total of 36 samples in the same city with regional alliance, a total sample of 65 respondents for the rest of the sample based on the basic information of commercial confidentiality and other reasons did not fill in the enterprise and the lack of. In addition, based on respondents from the industry environment by competitors, customers, suppliers, potential entrants and substitutes the unpredictable to determine where the industry dynamic enterprise high degree low, with the Likert seven point measurement. Based on the data collected from questionnaires, the industry dynamic average was 4.82 , higher than the average dynamic samples, there were 66 , less than the average dynamic samples, a total of 73. On the basis of this, the structural equation model analysis of the samples is carried out, and the results are shown in table 1 . The results show that the regional alliance, the path coefficient IT capability and alliance performance is $0.882(\mathrm{P}<0.001)$, and in the cross regional alliance, the coefficient is 0.735 $(\mathrm{P}<0.001)$ showed that, compared with the cross regional alliance, with the positive role of IT has stronger ability of regional alliance on alliance performance; hypothesis 2 support. In addition, in the high dynamic industry alliance capability and alliance performance path coefficient IT was $1.103(\mathrm{P}<0.001)$, and in the low dynamic industry alliance, the path coefficient of IT capability and alliance performance is $0.763(\mathrm{P}<0.001)$, shows that in the industry dynamic high, the ability of the positive role of enterprise IT the performance of alliance is bigger. Hypothesis 3 is also supported.

\section{Conclusion}

This paper focuses on the relationship between enterprise strategic alliance China in IT capability and alliance performance are discussed, the empirical test of the mediating effect of knowledge acquisition in between the two and the moderating effect of environmental factors on the relationship between the two. Based on the sample of 139 enterprise alliances and the analysis of structural equation model, this study draws the following conclusions:

First, the level of knowledge acquisition between firms in the alliance has a mediating effect between IT capability and alliance performance. The results confirmed the IT ability of enterprises is effective for enterprises to acquire knowledge 
from the alliance and efficiency; on the other hand, this study showed the effectiveness and efficiency of enterprise knowledge can help enterprises to obtain economic benefits and market returns from the Union in the process of cooperation, to better achieve its alliance strategy target. It needs to be emphasized is that results in knowledge acquisition is part of the intermediary role, but not completely intermediary role, namely the enterprise IT capability not only by improving the level of knowledge acquisition to achieve the promotion of alliance performance, but also by impact on other factors to have an effect on alliance performance, such as the relationship between alliance partners and the value chain activities in cooperation efficiency.

Second, in the context of the relationship between Chinese, regional and industry of the two environmental variables on IT capability and alliance performance has a significant moderating effect, the specific performance: compared with the cross regional alliance, with the positive role of regional cooperation alliance IT has stronger capability on alliance performance; compared with low dynamic industry, positive role in the industry of high dynamic alliance enterprise IT has stronger capability on alliance performance. This result supports the view of the scholars of market view and institutional foundation that the industry environment and regional environment of Chinese enterprises have a significant impact on corporate behavior and corporate performance. In the process of Chinese enterprises' alliance cooperation, the regional characteristics of the alliance partners, especially the regional institutional environment difference, may even play a more critical role in the effectiveness of the strategic behavior of enterprises.

\section{Acknowledgements}

The research is supported by National Humanities and Social Science in China under Grant 17BJR01063, Guangdong Natural Science Foundation under Grant 2014A030313442 and Guangzhou Philosophy and Social Science under Grant 2017GZYB43.

\section{References}

[1] Poppo L, Zhou K, and Li J. When Can You Trust "Trust"? Calculative Trust, Relational Trust, and Supplier Performance [J]. Strategic Management Journal, 2016, 37 (4): 724-741.

[2] Dyer J, Singh H, Kale P. Splitting the pie: rent distribution in alliances and networks [J]. Managerial and Decision Economics, 2008, 28 (2-3): 137-48.

[3] Weill P. The relationship between investment in information technology and firm performance: a study of the valve manufacturing sector [J]. Information Systems Research, 1992, 3 (4): 307-33.

[4] Bharadwaj A. A resource-based perspective on information technology capability and firm performance: an empirical investigation [J]. MIS Quarterly, 2000, 24 (1): 169-96.

[5] Santhanam R., Hartono E. Issues in linking information technology capability to firm performance [J]. MIS Quarterly, 2003, 27 (1): 125-65.

[6] Jean R. Enhancing international customer-supplier relationships through it resources: A study of Taiwanese electronics suppliers [J]. Journal of International Business Studies, 2010, 41 (4): 1218-39.

[7] Ravichandran T. et al. Diversification and firm performance: exploring the moderating effects of information technology spending [J]. Journal of Management Information Systems, 2009, 25 (4): 205-40.

[8] Liang T. P., You J. J., Liu C. C. A resource-based perspective on information technology and firm performance: a meta analysis [J]. Industrial Management \& Data Systems, 2010, 110 (8): $1138-58$.

[9] Schilke O, Cook K. Sources of Alliance Partner Trustworthiness: Integrating Calculative and Relational Perspectives [J]. Stragetic Management Journal, 2015, 36 (2): 276-297.

[10] Meier M. Knowledge management in strategic alliances: a review of empirical evidence [J]. International Journal of Management Reviews, 2011, 13 (3): 1-23.

[11] Becerra M., Lunnan R., Huemer L. Trustworthiness, risk, and the transfer of tacit and explicit knowledge between alliance partners [J]. Journal of Management Studies, 2008, 45 (4): 691-713.

[12] Weber B, Weber C. Corporate venture capital as a means of radical innovation: Relational fit, social capital and knowledge transfer [J]. Engineering Technology Management, 2007, 24 (1-2): 11-35.

[13] Lyles M., Salk J. Knowledge acquisition from foreign parents in international joint ventures: An empirical examination in the Hungarian context $[\mathrm{J}]$. Journal of International Business Studies, 2007, 38 (1): 3-18.

[14] Bouncecken R B, Clau T, Fredrich V. Product Innovation through Coopetition in Alliances: Singular or Plural Governance? [J]. Industrial Marketing Management, 2016, 53 (2): 77-90.

[15] Krishnan R, Geyskens I, Steenkamp J. The Effectiveness of Contractual and Trust-based Governance in Strategic Alliances Under Behavioral and Environmental Uncertainty [J]. Strategic Management Journal, 2016, 37 (12): 2521-2542.

[16] Kale $P$ and Singh H. Building firm capabilities through learning: the role of the alliance learning process in alliance capability and firm-level alliance success [J]. Strategic Management Journal, 2007, 28 (10): 981-1000. 